\title{
Psychosocial functioning before and after surgical treatment for morbid obesity: reliability and validation of the Norwegian version of obesity-related problem scale
}

Anny Aasprang, John Roger Andersen, Villy VV Våge, Ronette L Kolotkin, Gerd Karin Natvig

Background: The aims of this study were to translate the Obesity-Related Problem scale (OP scale) into the Norwegian language and test its reliability, validity and responsiveness in a Norwegian sample. Method: The questionnaire (OP scale) was translated from the original language (Swedish) into Norwegian. Patients completed the questionnaire prior to and one year after sleeve gastrectomy. Internal consistency was evaluated using Cronbach`s $\alpha$. Construct validity was tested by correlating the OP-scale with the SF-36 and the Cantril Ladder using the Pearson correlation coefficient. An exploratory and confirmatory factor analysis was used to test the unidimensionality of the OP scale. Responsiveness was tested by assessing changes in the OP scale from baseline to one year post-surgery using the paired sample t-test. Floor and ceiling effect were calculated as percentages. Results: A total of 181 patients (123 women) accepted for bariatric surgery was included in the study. The mean age was $43.1 \pm 12.5$ years, and mean body mass index (BMI) before surgery was $45 \pm 6.9$. The mean value of the OP scale at baseline was $63.30 \pm 24.43$ (severe impairment) and $21.01 \pm 20.98$ at one year follow-up (mild impairment). Internal consistency was high at baseline (Cronbach's $\alpha 0.91$ ). The floor effect was small at baseline and high at one year. The ceiling effect was small at baseline and at one year. Exploratory and conformatory factor analysis showed one factor with a high percent of explained variance. Correlations between OP scale at baseline, SF-36, Cantril Ladder and BMI were statistically significant and in the predicted direction to support validity of the Norwegian OP scale. After one year correlations between the change in OP scale and the change in SF-36 scores, Cantril Ladder and BMI were also statistically significant, except for the change in the Role Physical-scale. The OP scale showed greater responsiveness than either the SF-36 or Cantril Ladder. Conclusion: These results confirm that the Norwegian version of the OP scale is a valid and reliable instrument for measuring psychosocial functioning in patients with clinically severe obesity. 


\section{Psychosocial functioning before and after surgical treatment for morbid}

\section{2 obesity: Reliability and validity of the Norwegian version of obesity-related}

3 problems scale.

4 Anny Aasprang 1,5, John Roger Andersen 1,2, Villy Våge ${ }^{2}$, Ronette Kolotkin 1,2,3,4, and Gerd Karin Natvig ${ }^{5}$

$5 \quad{ }^{1}$ Faculty of Health Studies, Sogn og Fjordane University College, Førde, Norway

${ }^{2}$ Department of Surgery, Førde Central Hospital, Norway

${ }^{3}$ Obesity and Quality of Life Consulting, Durham, NC, US

${ }^{4}$ Duke University School of Medicine, Durham, NC, US

${ }^{5}$ Department of Global Public Health and Primary Care, University of Bergen, Norway

\section{Abstract}

Background: The aims of this study were to translate the Obesity-Related Problem scale (OP scale) into the Norwegian language and test its reliability, validity and responsiveness in a Norwegian sample.

Method: The questionnaire (OP scale) was translated from the original language (Swedish) into Norwegian. Patients completed the questionnaire prior to and one year after sleeve gastrectomy. Internal consistency was evaluated using Cronbach`s $\alpha$. Construct validity was tested by correlating the OP-scale with the SF-36 and the Cantril Ladder using the Pearson correlation coefficient. An exploratory and confirmatory factor analysis was used to test the unidimensionality of the OP scale. Responsiveness was tested by assessing changes in the OP scale from baseline to one year post-surgery using the paired sample t-test. Floor and ceiling effect were calculated as percentages.

Result: A total of 181 patients (123 women) accepted for bariatric surgery was included in the study. The mean age was $43.1 \pm 12.5$ years, and mean body mass index (BMI) before surgery was $45 \pm 6.9$. The mean value of the OP scale at baseline was $63.30 \pm 24.43$ (severe impairment) and $21.01 \pm 20.98$ at one year follow-up (mild impairment).

Internal consistency was high at baseline (Cronbach`s $\alpha$ 0.91). The floor effect was small at baseline and high at one year. The ceiling effect was small at baseline and at one year.

Exploratory and conformatory factor analysis showed one factor with a high percent of explained variance. Correlations between OP scale at baseline, SF-36, Cantril Ladder and BMI were statistically significant and in the predicted direction to support validity of the Norwegian OP scale. After one year correlations between the change in OP scale and the change in SF-36 
36 scores, Cantril Ladder and BMI were also statistically significant, except for the change in the

37 Role Physical-scale. The OP scale showed greater responsiveness than either the SF-36 or

38 Cantril Ladder.

39 Conclusion: These results confirm that the Norwegian version of the OP scale is a valid and

40 reliable instrument for measuring psychosocial functioning in patients with clinically severe

41 obesity.

42

43

44 Corresponding author

45 Anny.aasprang@hisf.no

46

47

48

49

50

51

52

53

54 


\section{Introduction}

Individuals with obesity often report reduced health-related quality of life (HRQL) compared to individuals with normal weight (Fontaine \& Barofsky 2001; Kolotkin et al. 2001b; Kushner \& Foster 2000; Larsson et al. 2002), and improvement in HRQL is one of the commonly stated objectives of surgical treatment of morbid obesity(Munoz et al. 2007). Several studies have shown a great improvement in HRQL after bariatric surgery (Aasprang et al. 2013; Helmio et al. 2011; Karlsson et al. 2007; Kolotkin et al. 2012; Schouten et al. 2011; Zijlstra H 2013) and the importance of evaluating HRQL and change in HRQL is underlined.

There are three basic approaches to measuring quality of life: disease-specific measures, generic measures and overall quality of life/life satisfaction. Both generic and disease-specific instruments are utilized to assess the burden of obesity (Fontaine \& Barofsky 2001; Kolotkin et al. 2001b; Kushner \& Foster 2000). Generic instruments focus on broad dimensions of health and do not cover all of the domains that are relevant for specific diseases, such as obesity. On the other hand disease-specific instruments are used to capture information that is most pertinent to particular patient groups (Karlsson et al. 2003). Overall quality of life is a subjective assessment of how happy or satisfied a person is with life as a whole (Wilson \& Cleary 1995). In the past decade several obesity-specific HRQL instruments have been introduced (Duval et al. 2006; Kolotkin et al. 2001a; Le Pen et al. 1998; Sullivan et al. 1993).

Psychosocial functioning is important in the assessment of HRQL in obesity (Sullivan et al. 1993), and weight related psychosocial distress is not assessed in generic instruments. The Obesity-Related Problems scale (OP scale) was developed in the Swedish Obese Subject Study (SOS) specifically to assess psychosocial problems related to obesity (Karlsson et al. 1998; 
Sullivan et al. 1993). The OP scale is scored so that lower scores represent higher psychosocial functioning. The OP scale has been used in several studies in different countries (Karlsson et al. 2007; Kaukua et al. 2003; Larusdottir et al. 2014; Oh et al. 2013; Sovik et al. 2013), but to our knowledge the OP scale has only been validated in the Swedish, Spanish and Korean languages. Results of these validation studies show that the OP scale has satisfactory reliability and validity (Bilbao et al. 2009; Karlsson et al. 2003; Lee et al. 2013). The OP scale has not been evaluated in surgical patients undergoing sleeve gastrectomy, nor has it been used prospectively, to our knowledge, with the exception of the SOS study.

The aims of this study were to translate the OP scale into the Norwegian language and test its reliability, validity and responsiveness in a Norwegian sample. The specific hypotheses were as follows: a) the Norwegian OP scale has satisfactory internal consistency; b) the variability of scores reflect one factor; c) the OP scale is negatively correlated with both the Cantril Ladder and Short form-36 ( SF-36), with the highest correlation coefficient with the social function domain of the SF-36;d) the OP scale is positively correlated with Body Mass Index (BMI); and e) changes in the OP scale are negatively correlated with changes in both the SF-36 and Cantril Ladder, as well as positively correlated with weight loss as assessed by changes in BMI.

\section{Materials and Methods}

\section{Study design and patients}

Before the study began we obtained permission from the author of the original Swedish OP scale to develop and validate a Norwegian version of the OP-scale. 
99

100

101

102

103

104

105

106

107

108

109

110

111

112

113

114

115

116

117

118

119

120

121

The cohort study was performed from 2011-2013 in the western region of Norway. A total of 209 patients accepted for bariatric surgery (sleeve gastrectomy) were invited to join the study. The inclusion criteria were age $18-60$ years, $\mathrm{BMI} \geq 40.0$ or 35.0-39.9 with obesity- related comorbidities, no active psychosis, no drug or alcohol problems, and previous failure to lose weight through other methods. Written informed consent was obtained from participants to complete self-report questionnaires prior to and one year after sleeve gastrectomy. The patients completed the questionnaires at home and brought them to the hospital when they arrived for surgery (baseline) and one-year follow-up. Those who had forgotten the questionnaires were allowed to complete the questionnaires at the hospital. The investigation conforms to the principles outlined in the Declaration of Helsinki. The study was approved by the Regional Committee of Ethics in Medicine, West-Norway (reference number: 2009/2174).

\section{Demographic characteristics and clinical data}

Data were collected using a standardized form. Body weight, height, age, gender, educational

level, marital status and employment status of the patients were noted. Body weight was measured in light clothing without shoes to the nearest $0.1 \mathrm{~kg}$. Height was measured in a standing position without shoes to the nearest $0.01 \mathrm{~m}$. Body mass index (BMI) was calculated as weight divided by height squared $\left(\mathrm{kg} / \mathrm{m}^{2}\right)$.

\section{Questionnaires administered}

The OP scale is an 8-item questionnaire developed for the SOS study to measure the impact of obesity on psychosocial functioning (Karlsson et al. 2003; Sullivan et al. 1993). The OP scales asks respondents to rate on a 4-point scale ("definitely not bothered", "not so bothered", "mostly 
122 bothered" and "definitely bothered") if their obesity bothers them in activities such as private

123 gatherings, community activities, and intimate relations. The scale is coded so that lower scores

124 represent higher psychosocial functioning. Scores on individual items are summed to create a

125 raw total score, which can vary between 8 and 32. This score is standardized on a scale from $0-$

126100 , where 100 indicates the worst possible state and 0 the best possible state. Scores below 20

127 indicate no or very mild impairment in psychosocial functioning. Scores between 20 and $<40$

128 indicate mild impairment, between 40 and $<60$ moderate impairment, between 60 and $<80$

129 severe impairment and 80 or above extreme impairment (Karlsson 2003). We used version 2 of

130 the OP scale.

131

132 The Short Form -36 (SF-36) (Norwegian version 1.2) is a well-established generic measure of

133 the health burden of chronic diseases (Ware 2000). The questionnaire has demonstrated good

134 validity and reliability(Loge \& Kaasa 1998). SF-36 assesses eight dimensions of physical and

135 mental functioning, each ranging from zero (poorest) to 100 (optimal). The subscales physical

136 functioning, physical role function and bodily pain reflect physical functioning, and emotional

137 role function and mental health reflect mental functioning. The subscales general health, vitality

138 and social functioning reflect both physical and mental functioning. The SF-36 can also be

139 divided into two summary scores, Physical Component Summary (PCS) and Mental Component

140 Summary (MCS) (Ware JE 2000), where a higher score represents better physical or mental

141 health. PCS and MCS scores are standardized so that a difference in 2- 4.9 points, respectively,

142 can be interpreted as a small effect size, 5-7.9 points, respectively, a medium effect size and 8+

143 points a large effect size (Cohen 1988; Saris-Baglama 2004). 
145 Cantril Ladder is used to assess life satisfaction. The term life satisfaction is often used to 146 describe quality of life, well-being and happiness. Respondents rate their current life satisfaction 147 on a ladder ranging from 10 to 0 , where 10 reflects the best life satisfaction and 0 reflects the 148 worst life satisfaction. A score below 6 is considered to be low life satisfaction, and a score of 6 149 or more is considered to be high life satisfaction (Levin 2014).

152 The OP scale was translated from the original language (Swedish) into Norwegian, according to

153 the standards established by the International Quality of Life Assessment Project group

154 (Aaronson et al. 1992; Guillemin et al. 1993). Translation from Swedish to Norwegian was

155 conducted by two individuals whose native language was Norwegian and who have a clear

156 understanding of conceptual meanings in both Norwegian and Swedish languages. The

157 translators were health professionals and were professionally familiar with the concept of morbid

158 obesity. The back translation from Norwegian to Swedish was conducted by two other

159 individuals with an academic background from the social sciences who had Swedish as their

160 native language, as well as a clear understanding of conceptual meanings in both Swedish and

161 Norwegian. The translators worked separately during this phase. A consensus panel of three

162 people compared the original version with the two translated versions and reconciled the forward 163 translations into one common version. 
165 The Norwegian version of the questionnaire was tested on a small sample of patients $(\mathrm{n}=8)$ who

166 had been accepted for bariatric surgery. The aim of the pilot study was to identify and solve any

167 potential problems in the translations, such as confusing words. The patients gave feedback in

168 focus groups composed of four individuals $(4+4)$. The questionnaire was found to be easily

169 understood, and no changes to the questionnaire were required.

\section{Statistical Analysis}

172 Clinical and sociodemographic data were described as frequency and percentages or means \pm 173 standard deviation (SD).

Internal consistency for the OP scale was calculated using Cronbach`s $\alpha$. Cronbach`s $\alpha$ above 0.7 was considered to be satisfactory (Cohen 1988). We also calculated Cronbach`s $\alpha$ if one item was deleted. As an addition analysis we correlated the items of the OP score with the total score, and we corrected for overlap. In order to study structure validity, we performed a principal component analysis (PCA) to test whether the items on the OP-scale made up a single factor. The items with factor loading and communality $\geq 0.40$ were considered acceptable (Staquet MJ 1998). To complement our results we performed a confirmatory factor analysis (CFA), using the following indexes and cut-offs indicating acceptable fit (Batista-Foguet et al. 2004; Devins et al. 2001; Hatcher 1994; Mulaik 1989): (a) chi squared divided by the degrees of freedom ( $\left.\chi^{2} / \mathrm{DF}\right)$ $(<2)$; (b) the root mean squared error of approximation (RMSEA), $(<0.08)$; and (c) the normed fit index (NFI) ( $>90)$ and comparative fit index (CFI) $(>90)$. CFA factor loadings $\geq 0.40$ were considered acceptable (Staquet MJ 1998). 
Convergent validity was tested by correlating the OP scale with the SF-36, Cantril Ladder, and BMI, using the Pearson correlation coefficient. A value of $<0.1$ was considered as trivial, 0.10.29 as small, $0.3-0.49$ as moderate and values $\geq 0.5$ as large (Cohen 1988). We tested the association between OP scale and gender by independent T-tests and the association between OP scale and age by Pearson correlation.

A change in OP scale, Cantril ladder and SF-36 from baseline to one year post-surgery was tested using the paired sample t-test. Magnitude of responsiveness was studied by calculating effect sizes (i.e. mean change between assessments, divided by the standard deviation of change)(Cohen 1988). An effect size $<0.2$ was considered as trivial, $0.2-<0.5$ as small, $0.5-$ $<0.8$ as moderate and large $\geq 0.8)($ Cohen 1988). Comparison of baseline characteristics between responders and non-responders to the follow up was tested by chi-squared (categorical variable) and independent T-test (continuous variables). Floor and ceiling effects were calculated as percentages. Floor or ceiling effects should be below $15 \%$ to meet acceptable measurement standards (Wyrwich et al. 1999).

Given a significance level of 0.05 and a power of $80 \%$ we would be able to detect a significant correlation of 0.24 or more between $\mathrm{OP}$ scale and other measures when $\mathrm{N}=130$. Statistical analyses were performed with the statistical program Statistical Package for Social Sciences, for windows, version 22.0 (SPSS, Chicago, IL). CFA was conducted using an add-on feature of SPSS Inc. software, AMOS Version 22.0.0. 


\section{Results}

211 Figure 1 describes the flow of patients through the study. A total of 209 patients were invited to

212 participate in the study. Baseline analyses were based on 181 patients, and follow-up analyses

213 were based on 130 patients. Among the 181 included patients 123 (68\%) were female. Patient

214 characteristics are presented in Table 1 . The mean age was $43.1 \pm 12.5$ years, and mean body

215 mass index before surgery was $45 \pm 6.9$. The attrition rates (14\%) at the 1-year follow-up was

216 higher in women $(\mathrm{p}=0.013)$ and in those who had a lower score on the Cantril Ladder at baseline

$217(\mathrm{p}=0.002)$.

In Table 2 statistics are presented for OP scale item-total correlations, Cronbach's $\alpha$, exploratory factor analysis factor loadings and item communalities at baseline. The patients completed all the items in the OP scale so we had no missing data. Item-total correlations correcting for overlap ranged from 0.53 to 0.80 . Cronbach's $\alpha$ for the OP-scale total score was 0.91 . Cronbach's $\alpha$ if one item deleted ranged from 0.89 to 0.91 for OP scale items. The PCA showed that a single and item communalities from 0.39 to 0.74 . The CFA showed that the modification indices (M.I) indicated a high covariance between item 1 and 2 (M.I $=21.37$, Par change $=0.135)$. This could be related to the items having quite similar wording about attending a party and that the items are placed after each other in the questionnaire. Thus we let the error terms of item 1 and 2 covariate in the model resulting in an improved model fit. The results of the CFA were as follows: $\chi^{2}$ /DF

$230=1.89, \mathrm{RMSEA}=0.070, \mathrm{NFI}=0.96$ and $\mathrm{CFI}=0.98$. Factor loadings ranged from 0.55 to 0.86 $231 \quad(\mathrm{Ps}<0.001)$. 
233 At baseline the correlation coefficients between the OP scale and all the self-reported measures

234 and BMI were statistically significant and in the predicted direction (Table 3).We found no

235 association between OP scale and age and gender (data not shown). After one year the

236 correlation coefficients between the change in OP scale and the change in self-reported measures

237 and change in BMI were also statistically significant, except for the change in the RP-scale

238 (Table 3).

239

240 The mean value of the OP-scale was $63.30 \pm 24.43$ (severe impairment) at baseline and $21.01 \pm$

24120.98 (mild impairment) at 1 year (Table 4). Mean scores for the SF-36 and Cantril Ladder are

242 also presented in Table 4, as well as results of the paired samples t-test to evaluate the

243 responsiveness of changes in the OP scale following surgery. The OP scale had a higher

244 responsiveness (ES 1.7) than the SF-36 (PCS 1.5, MCS 1.0) and Cantril Ladder (ES 1.4). The

245 percentage of patients scoring at the lowest possible level (floor effect) was $1.1 \%$ at baseline and

$24620 \%$ at 1 year. The percentage score at the highest possible level (ceiling effect) was $3.9 \%$ at

247 baseline and $0 \%$ at 1 year.

\section{Discussion}

250 Our aim was to translate the OP scale into the Norwegian language and to tests its psychometric

251 properties and responsiveness in a group of severely obese Norwegians prior to and one year

252 after bariatric surgery. The study shows that the Norwegian version of the OP scale is a reliable

253 and valid instrument. The SOS study showed that the OP scale's psychometric properties were 
254 strongly supported, and our results reproduced the same good performance in terms of validity

255 and reliability (Karlsson et al. 2003).

It has also been shown that the OP scale is valid and reliable for use in Spain and Korea (Bilbao et al. 2009; Lee et al. 2013). Our study population is similar to the study population in other validation studies of the OP scale (i.e. bariatric surgery patients) (Bilbao et al. 2009; Karlsson et al. 2003). The mean OP score in our sample prior to surgery was similar to the Korean validation study (Lee et al. 2013) but a little higher than in the original Swedish study and in the Spanish validation study (Bilbao et al. 2009; Karlsson et al. 2003) .

In our study the internal consistency was above the recommended value $>0.70$ (Nunnally JC 1994) which confirms the hypothesis that the Norwegian version of the OP scale has satisfactory internal consistency. This is a similar result as in other validation studies of the OP scale (Bilbao et al. 2009; Karlsson et al. 2003; Lee et al. 2013).

The factor analysis results confirm the unidimensionality of the OP scale. The majority of the total variance is explained by one factor with a high percentage of the variance explained by this factor, similar to that found by the authors of the original questionnaire (Karlsson et al. 2003) and in the Spanish version (Bilbao et al. 2009). The convergent validity of the OP scale was assessed by examining the relationship between the OP scale and SF-36 and Cantril Ladder. High levels of convergent validity were found. The OP scale had significant negative correlation with all eight domains and the two summary measures of SF-36 and also for Cantril Ladder at baseline. The OP scale had a lower correlation coefficient with role physical and higher 
276

277

278

279

280

281

282

283

284

285

286

287

288

289

290

291

292

293

294

295

296

297

correlation coefficient with the social function domain. This is not surprising given that OP scale measures one aspect of psychosocial functioning. These last findings have been reported by Bilbao et al. (Bilbao et al. 2009). BMI showed a significant positive correlation with the OP scale, as was found in other studies (Bilbao et al. 2009; Karlsson et al. 2003).

We found significant negative correlations between changes in OP scale and changes in the SF36 (all the domains and the two summary scores), except for physical role function. This is likely explained by the response categories for physical role which have a low degree of precision (yes versus no). As far as we know, there have not been any previously published studies describing correlations of change scores for the OP scale. Change in life satisfaction was also significant negative correlated with the OP scale, which means that there is a strong relationship between life satisfaction and psychosocial functioning.

Responsiveness of change in OP scale and other self-report measures was analysed by comparing changes in OP scale, SF-36 and Cantril Ladder at baseline and one year after surgery. The OP scale was more responsive to change compared than the SF-36 and Cantril Ladder. These findings are similar to the OP scale in Sweden, where the questionnaire was developed (Karlsson et al. 2003). Other validation studies have not tested the responsiveness before and after surgery (Bilbao et al. 2009; Lee et al. 2013).

Baseline floor and ceiling effects of the OP scale were small, similar to the original version. It is desired that ceiling and floor effect should be minimal (Karlsson et al. 2003). We found floor effects at $20 \%$ at one-year follow-up (20\% of participants scored at the best possible state). This 
might suggests that the OP scale might lack the ability to capture changes occurring over time for

299

300

301

302

303

304

305

306

307

308

309

310

311

312

313 given individuals. However it is perhaps more likely that having the best possible score actually means that the patients have no problems.

The OP scale measures the impact of obesity on psychosocial functioning. A limitation of the present study is that the OP scale was only validated in a group of patients that had been accepted for bariatric surgery (BMI $\geq 35$ ), and it is therefore unknown if the Norwegian OP scale is equally valid, reliable, and responsive in other groups of individuals with obesity, for example patients with a BMI between 30 and 35. It is unclear how the small attrition rate (14\%) influenced the results. A strength of the study is, however, that we studied responsiveness from baseline to one year after surgery, and it also strengthens the study that we compared the OP scale with well validated HRQL instruments. Finally, as far as we know, this is the first study that has used correlation of change scores in the validation of OP scale.

In conclusion this Norwegian version of the OP scale is a valid and reliable instrument for measuring psychosocial functioning in a sample with clinically severe obesity in Norway.

Acknowledgements we thank L Schjelderup by department of Surgery, Førde Central Hospital, for assisting with the data collection. 


\section{References}

Aaronson NK, Acquadro C, Alonso J, Apolone G, Bucquet D, Bullinger M, Bungay K, Fukuhara S, Gandek B, Keller S, and et al. 1992. International Quality of Life Assessment (IQOLA) Project. Qual Life Res 1:349-351.

Aasprang A, Andersen JR, Vage V, Kolotkin RL, and Natvig GK. 2013. Five-year Changes in Health-Related Quality of Life after Biliopancreatic Diversion with Duodenal Switch. Obes Surg.

Batista-Foguet JM, Coenders G, and Alonso J. 2004. [Confirmatory factor analysis. Its role on the validation of health related questionnaires]. Med Clin (Barc) 122 Suppl 1:21-27.

Bilbao A, Mar J, Mar B, Arrospide A, Martinez de Aragon G, and Quintana JM. 2009. Validation of the Spanish translation of the questionnaire for the obesity-related problems scale. Obes Surg 19:1393-1400.

Cohen J. 1988. Statistical power analysis for the behavioral sciences. Hillsdale: Lawrence Erlbaum Associates.

Devins GM, Dion R, Pelletier LG, Shapiro CM, Abbey S, Raiz LR, Binik YM, McGowan P, Kutner NG, Beanlands H, and Edworthy SM. 2001. Structure of lifestyle disruptions in chronic disease: a confirmatory factor analysis of the Illness Intrusiveness Ratings Scale. Med Care 39:1097-1104.

Duval K, Marceau P, Perusse L, and Lacasse Y. 2006. An overview of obesity-specific quality of life questionnaires. Obesity Reviews 7:347-360.

Fontaine KR, and Barofsky I. 2001. Obesity and health-related quality of life. Obes Rev 2:173-182.

Guillemin F, Bombardier C, and Beaton D. 1993. Cross-cultural adaptation of health-related quality of life measures: literature review and proposed guidelines. J Clin Epidemiol 46:1417-1432.

Hatcher L. 1994. Developing measurement models with confirmatory factor analysis. A step-by-step approach to using SAS System for factor analysis and structual equationmodelling. Cary, NC:USA: SAS Institute Inc.

Helmio M, Salminen P, Sintonen H, Ovaska J, and Victorzon M. 2011. A 5-year prospective quality of life analysis following laparoscopic adjustable gastric banding for morbid obesity. Obes Surg 21:1585-1591.

Karlsson J, Sjostrom L, and Sullivan M. 1998. Swedish obese subjects (SOS)--an intervention study of obesity. Two-year follow-up of health-related quality of life (HRQL) and eating behavior after gastric surgery for severe obesity. Int J Obes Relat Metab Disord 22:113-126.

Karlsson J, Taft C, Ryden A, Sjöström L, and Sullivan M. 2007. Ten-year trends in health-related quality of life after surgical and conventional treatment for severe obesity: the SOS intervention study. Int J Obes 31:1248-1261.

Karlsson J, Taft C, Sjostrom L, Torgerson JS, and Sullivan M. 2003. Psychosocial functioning in the obese before and after weight reduction: construct validity and responsiveness of the Obesity-related Problems scale. Int J Obes Relat Metab Disord 27:617-630.

Kaukua J, Pekkarinen T, Sane T, and Mustajoki P. 2003. Health-related quality of life in obese outpatients losing weight with very-low-energy diet and behaviour modification--a 2-y follow-up study. Int J Obes Relat Metab Disord 27:1233-1241.

Kolotkin RL, Crosby RD, Kosloski KD, and Williams GR. 2001a. Development of a brief measure to assess quality of life in obesity. Obes Res 9:102-111.

Kolotkin RL, Davidson LE, Crosby RD, Hunt SC, and Adams TD. 2012. Six-year changes in health-related quality of life in gastric bypass patients versus obese comparison groups. Surg Obes Relat Dis 8:625-633.

Kolotkin RL, Meter K, and Williams GR. 2001b. Quality of life and obesity. Obes Rev 2:219-229.

Kushner RF, and Foster GD. 2000. Obesity and quality of life. Nutrition 16:947-952. 
Larsson U, Karlsson J, and Sullivan M. 2002. Impact of overweight and obesity on health-related quality of life--a Swedish population study. International Journal of Obesity and Related Metabolic Disorders 26:417-424.

Larusdottir H, Saevarsdottir H, Steingrimsdottir L, Guethmundsson L, and Arnarson EO. 2014. [The effectiveness of the treatment program "Enjoy eating" on health and mood in obese women]. Laeknabladid 100:27-33.

Le Pen C, Levy E, Loos F, Banzet MN, and Basdevant A. 1998. "Specific" scale compared with "generic" scale: a double measurement of the quality of life in a French community sample of obese subjects. J Epidemiol Community Health 52:445-450.

Lee YJ, Moon KH, Choi JH, Cho MJ, Shin SH, and Heo Y. 2013. Validation of the Korean translation of obesity-related problems scale assessing the quality of life in obese Korean. J Korean Surg Soc 84:140-153.

Levin KAC, C. 2014. Reliability and Validity of an Adapted Version af the Cantril Ladder for Use with Adolescent Samples. Social Indicators Research 119:1047-1063.

Loge JH, and Kaasa S. 1998. Short form 36 (SF-36) health survey: normative data from the general Norwegian population. Scand J Soc Med 26:250-258.

Mulaik S. 1989. Evaluation of godness-of-fit indices for structural equation models. Psychol Bull 105:430445.

Munoz DJ, Lal M, Chen EY, Mansour M, Fischer S, Roehrig M, Sanchez-Johnsen L, Dymek-Valenitine M, Alverdy J, and le Grange D. 2007. Why patients seek bariatric surgery: a qualitative and quantitative analysis of patient motivation. Obes Surg 17:1487-1491.

Nunnally JC BI. 1994. Psychometric theory. New Yourk: McGraw-Hill.

Oh SH, Song HJ, Kwon JW, Park DJ, Lee YJ, Chun H, Kim S, and Shim KW. 2013. The improvement of quality of life in patients treated with bariatric surgery in Korea. J Korean Surg Soc 84:131-139.

Saris-Baglama RN, Deway, C.J.,Chisholm, G.B., Kosinski, M., Bjorner, j.b., Ware, J.E.Jr., . 2004. SF Health Outcomes $^{\text {TM }}$ Scoring Software User's Guide.

Schouten R, Wiryasaputra DC, van Dielen FM, van Gemert WG, and Greve JW. 2011. Influence of reoperations on long-term quality of life after restrictive procedures: a prospective study. Obes Surg 21:871-879.

Sovik TT, Karlsson J, Aasheim ET, Fagerland MW, Bjorkman S, Engstrom M, Kristinsson J, Olbers T, and Mala T. 2013. Gastrointestinal function and eating behavior after gastric bypass and duodenal switch. Surg Obes Relat Dis 9:641-647.

Staquet MJ HR, Fayers PM. 1998. Quality of life assessment in clinical trials. Oxdord: Oxford Press.

Sullivan M, Karlsson J, Sjostrom L, Backman L, Bengtsson C, Bouchard C, Dahlgren S, Jonsson E, Larsson B, Lindstedt S, and et al. 1993. Swedish obese subjects (SOS)--an intervention study of obesity. Baseline evaluation of health and psychosocial functioning in the first 1743 subjects examined. Int J Obes Relat Metab Disord 17:503-512.

Ware J. 2000. SF-36 Health Survey: Manual \& Interpretation Guide: Lincoln, RI:Quality Metric Incorporated.

Ware JE KM, Dewey JE. 2000. How to Score Version 2 of the SF-36 Health Syrvey.

Wilson IB, and Cleary PD. 1995. Linking clinical variables with health-related quality of life. A conceptual model of patient outcomes. Jama 273:59-65.

Wyrwich KW, Tierney WM, and Wolinsky FD. 1999. Further evidence supporting an SEM-based criterion for identifying meaningful intra-individual changes in health-related quality of life. $J$ Clin Epidemiol 52:861-873.

Zijlstra H LJ, Wouters EJM, Ramshorst BV, Geenen R. 2013. The Long-Term Course of Quality of Life and the Prediction of Weight Outcome After Laparoscopic Adjustable Gastric Banding: A Prospective Study Bariatric Surgical Patient Care 8:18-22. 


\section{Figure 1 (on next page)}

Flow of patients

*Excluded due to problems with the data-gathering routines. ** For 26 of the patients we had no postsurgery data because there was less than a year since surgery. Three patients did not meet for follow-op appointment, 21 were excluded due to problems with the data-gathering routines and one had the control with his GP and did not send the questionnaire to the hospital. 


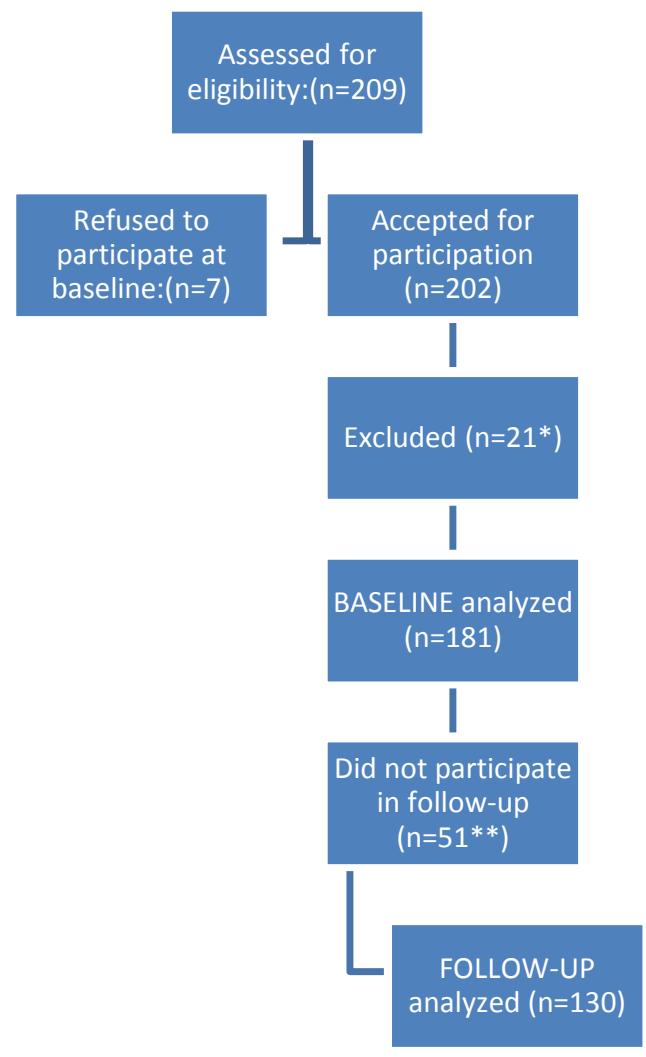




\section{Table 1 (on next page)}

Characteristics of the patients $(n=181)$

SD standard deviation. Number of patients ranges from 179-181 


\begin{tabular}{|l|l|}
\hline Variable & Value \\
\hline Age $(\mathrm{yr})$, mean $\pm \mathrm{SD}$ & $43.1 \pm 12.5$ \\
\hline Gender, Woman, $\mathrm{n}(\%)$ & $123(68.0)$ \\
\hline Mean body mass index $\left(\mathrm{kg} / \mathrm{m}^{2}\right.$ ) baseline, mean \pm SD & $45.0 \pm 6.9$ \\
\hline Current marital status, $\mathbf{n}(\%)$ & $114(63.0)$ \\
Married/cohabitants & $66(37.0)$ \\
Live alone & \\
\hline Education, $\mathbf{n}(\%)$ & $42(23.2)$ \\
Primary school & $96(53.0)$ \\
High school & $28(15.5)$ \\
University $\leq 4 \mathrm{y}$ & $13(7.2)$ \\
University $>4 \mathrm{y}$ & \\
& \\
\hline
\end{tabular}

2 
Table 2 (on next page)

Reliability analyses and exploratory and confirmatory factor analyses $(n=181)$

Standarized Cronbach`s $\alpha$ of OP scale baseline 0.91 . The PCA showed that a single factor explained $62.2 \%$ of the variance in the OP-scale. a The item total correlation with its own OP scale correcting for overlap. 


\begin{tabular}{|c|c|c|c|c|c|c|}
\hline Item & $\begin{array}{l}\text { Item } \\
\text { description }\end{array}$ & $\begin{array}{l}\text { Item-total } \\
\text { correlation }^{\mathrm{a}}\end{array}$ & $\begin{array}{l}\alpha \text { if one } \\
\text { item } \\
\text { deleted }\end{array}$ & $\begin{array}{l}\text { Exploratory } \\
\text { factor } \\
\text { analysis } \\
\text { loading }\end{array}$ & $\begin{array}{l}\text { Exploratory } \\
\text { factor } \\
\text { analysis } \\
\text { Communality }\end{array}$ & $\begin{array}{l}\text { Confirmatory } \\
\text { factor } \\
\text { analysis } \\
\text { loading }\end{array}$ \\
\hline 1 & $\begin{array}{l}\text { Private } \\
\text { gatherings } \\
\text { in my own } \\
\text { home }\end{array}$ & 0.69 & 0.90 & 0.77 & 0.60 & 0.70 \\
\hline 2 & $\begin{array}{l}\text { Private } \\
\text { gatherings } \\
\text { in a } \\
\text { friend`s } \\
\text { home }\end{array}$ & 0.80 & 0.89 & 0.86 & 0.74 & 0.82 \\
\hline 3 & $\begin{array}{l}\text { Going to a } \\
\text { restaurant }\end{array}$ & 0.80 & 0.89 & 0.86 & 0.74 & 0.86 \\
\hline 4 & $\begin{array}{l}\text { Going to } \\
\text { community } \\
\text { activities }\end{array}$ & 0.72 & 0.90 & 0.84 & 0.70 & 0.83 \\
\hline 5 & $\begin{array}{l}\text { Holidays } \\
\text { away from } \\
\text { home }\end{array}$ & 0.78 & 0.89 & 0.84 & 0.71 & 0.83 \\
\hline 6 & $\begin{array}{l}\text { Trying and } \\
\text { buying } \\
\text { clothes }\end{array}$ & 0.66 & 0.91 & 0.74 & 0.54 & 0.69 \\
\hline 7 & $\begin{array}{l}\text { Bathing in } \\
\text { public } \\
\text { places }\end{array}$ & 0.53 & 0.91 & 0.62 & 0.39 & 0.55 \\
\hline 8 & $\begin{array}{l}\text { Intimate } \\
\text { relations } \\
\text { with } \\
\text { partner }\end{array}$ & 0.67 & 0.90 & 0.745 & 0.56 & 0.69 \\
\hline
\end{tabular}

2

3

4

5

6

7

8

9

10 
Table 3 (on next page)

Correlations between OP scale, SF-36 and Cantril Ladder at baseline and between changes in these scores after one year.

: $\Delta=$ change, $\mathrm{SD}=$ standard deviation, $\mathrm{PCS}=$ physical component summary, $\mathrm{MCS}=$ mental component summary. Since a higher score on the OP scale indicates poorer psychosocial functioning, the correlation between change in OP scale and change in SF-36 and Cantril Ladder is negative

Data are given as Pearson`s $r$ correlation coefficients. P values $<0.05$ were considered statistically significant 


\begin{tabular}{|c|c|c|}
\hline & $\begin{array}{l}\text { OP Baseline } \\
\text { ( } \mathrm{n} \text { ranged from } 175 \text { to } 181 \text { ) }\end{array}$ & $\begin{array}{l}\triangle \mathrm{OP} \\
\text { ( } \mathrm{n} \text { ranged from } 124 \text { to } 130 \text { ) }\end{array}$ \\
\hline Life satisfaction Baseline & $-.561(p<0.001)$ & \\
\hline BMI Baseline & $.186(p=0.012)$ & \\
\hline \multicolumn{3}{|l|}{ SF-36 } \\
\hline PCS Baseline & $-.410(p<0.001)$ & \\
\hline MCS Baseline & $-.624(p<0.001)$ & \\
\hline Physical function & $-.321(p<0.001)$ & \\
\hline Physical role function & $-.268(p<0.001)$ & \\
\hline Bodily pain & $-.299(p<0.001)$ & \\
\hline General Health & $-.367(p<0.001)$ & \\
\hline Vitality & $-.460(p<0.001)$ & \\
\hline Social function & $-.582(p<0.001)$ & \\
\hline Emotional role function & $-.373(p<0.001)$ & \\
\hline Mental health & $-.570(p<0.001)$ & \\
\hline$\Delta$ Life satisfaction & & $-.394(p<0.001)$ \\
\hline$\Delta \mathrm{BMI}$ & & $-.280(p<0.001)$ \\
\hline \multicolumn{3}{|l|}{$\Delta$ SF-36 } \\
\hline$\triangle \mathrm{PCS}$ & & $-.248(p=0.006)$ \\
\hline$\triangle \mathrm{MCS}$ & & $-.339(p<0.001)$ \\
\hline$\Delta$ Physical function & & $-.266(p=0.002)$ \\
\hline$\Delta$ Physical role function & & $-.091(p=0.306)$ \\
\hline$\Delta$ Bodily pain & & $-.193(p=0.028)$ \\
\hline$\Delta$ General Health & & $-.229(p=0.009)$ \\
\hline$\Delta$ Vitality & & $-.255(p=0.004)$ \\
\hline$\Delta$ Social function & & $-.328(p<0.001)$ \\
\hline$\Delta$ Emotional role function & & $-.221(p=0.013)$ \\
\hline$\Delta$ Mental health & & $-.250(p=0.004)$ \\
\hline
\end{tabular}

2 


\section{Table 4(on next page)}

Mean score on OP scale, SF-36 and Cantril Ladder at baseline and at one year post-surgery

SD standard deviation, ES effect size, PCS physical component summary, MCS mental component summary. 


\begin{tabular}{|l|l|l|l|l|}
\hline Scores & $\begin{array}{l}\text { Baseline } \\
\text { Mean (SD) } \\
(\mathrm{n}=130)\end{array}$ & $\begin{array}{l}1 \text { year post-surgery } \\
\text { Mean (SD) } \\
(\mathrm{n}=130)\end{array}$ & p-value & ES \\
\hline OP scale & $63.30(24.43)$ & $21.08(20.98)$ & $<0.001$ & 1.7 \\
\hline Cantril Ladder & $5.01(1.81)$ & $7.49(1.51)$ & $<0.001$ & 1.4 \\
\hline SF-36 & & & & \\
\hline PCS & $37.41(9.56)$ & $51.90(8.93)$ & $<0.001$ & 1.5 \\
\hline MCS & $42.82(10.40)$ & $53.35(9.44)$ & $<0.001$ & 1.0 \\
\hline Physical function & $58.19(21.99)$ & $88.51(16.68)$ & $<0.001$ & 1.4 \\
\hline Physical role function & $41.03(38.03)$ & $80.96(31.56)$ & $<0.001$ & 1.1 \\
\hline Bodily pain & $49.44(24.63)$ & $69.92(26.16$ & $<0.001$ & 0.8 \\
\hline General Health & $46.99(20.01)$ & $78.36(19.51)$ & $<0.001$ & 1.6 \\
\hline Vitality & $35.69(18.32)$ & $61.23(22.02)$ & $<0.001$ & 1.4 \\
\hline Social function & $64.60(28.38)$ & $88.65(19.02)$ & $<0.001$ & 0.8 \\
\hline Emotional role function & $64.06(39.60)$ & $89.58(27.35)$ & $<0.001$ & 0.6 \\
\hline Mental health & $69.84(14.72)$ & $82.12(15.43)$ & $<0.001$ & 0.7 \\
\hline
\end{tabular}

2 